\title{
How well are we managing fragility hip fractures? A narrative report on the review with the attempt to set up a Fragility Fracture Registry in Hong Kong
}

\author{
KS Leung *, WF Yuen, WK Ngai, CY Lam, TW Lau, KB Lee, KM Siu, N Tang, SH Wong, WH Cheung
}

\section{A B S T R A C T}

Introduction: In setting up a disease registry for fragility fractures in Hong Kong, we conducted a retrospective systematic study on the management of fragility hip fractures. Patient outcomes were compared with the standards from our orthopaedic working group and those from the British Orthopaedic Association that runs a mature fracture registry in the United Kingdom.

Methods: Clinical data on fragility hip fracture patients admitted to six acute major hospitals in Hong Kong in 2012 were captured. These included demographics, pre- and post-operative assessments, discharge details, complications, and 1-year followup information. Analysis was performed according to the local standards with reference to those from the British Orthopaedic Association.

Results: Overall, $91.0 \%$ of patients received orthopaedic care within 4 hours of admission and $60.5 \%$ received surgery within 48 hours. Preoperative geri-orthopaedic co-management was received by $3.5 \%$ of patients and was one of the reasons for the delayed surgery in $22 \%$ of patients. Only $22.9 \%$ were discharged with medication that would promote bone health. Institutionalisation on discharge significantly increased by $16.2 \%(\mathrm{P}<0.001)$. Only $35.1 \%$ of patients attended out-patient followup 1 year following fracture, and mobility had deteriorated in $69.9 \%$ compared with the premorbid state. Death occurred in $17.3 \%$ of patients within a year of surgery compared with $1.6 \%$ mortality rate in a Hong Kong age-matched population.

This article was published on 5 May 2017 at www.hkmj.org.
Conclusions: The efficiency and quality of acute care for fragility hip fracture patients was documented. Regular geri-orthopaedic co-management can enhance acute care. Much effort is needed to improve functional recovery, prescription of bone health medications, attendance for follow-up, and to decrease institutionalisation. A Fracture Liaison Service is vital to improve long-term care and prevent secondary fractures.

Hong Kong Med J 2017;23:264-71

DOI: 10.12809/hkmj166124

${ }^{1}$ KS Leung *, MD, FHKCOS

${ }^{1}$ WF Yuen, BNurs, MSc

${ }^{2}$ WK Ngai, MB, BS, FHKCOS

${ }^{3}$ CY Lam, MB, BS, FHKCOS

${ }^{4}$ TW Lau, MB, BS, FHKCOS

${ }^{5}$ KB Lee, MB, ChB, FHKCOS

${ }^{6} \mathrm{KM} \mathrm{Siu,} \mathrm{MB}, \mathrm{ChB}$, FHKCOS

${ }^{7} \mathrm{~N}$ Tang, MB, ChB, FHKCOS

${ }^{8}$ SH Wong, MB, BS, FHKCOS

${ }^{1}$ WH Cheung, BSc, PhD

1 Department of Orthopaedics and Traumatology, The Chinese University of Hong Kong, Shatin, Hong Kong

Department of Orthopaedics and Traumatology, North District Hospital, Sheung Shui, Hong Kong

${ }^{3}$ Department of Orthopaedics and Traumatology, Tuen Mun Hospital, Tuen Mun, Hong Kong

${ }^{4}$ Department of Orthopaedics and Traumatology, Queen Mary Hospital, Pokfulam, Hong Kong

${ }^{5}$ Department of Orthopaedics and Traumatology, Queen Elizabeth Hospital, Jordan, Hong Kong

${ }^{6}$ Department of Orthopaedics and Traumatology, Princess Margaret Hospital, Laichikok, Hong Kong

Department of Orthopaedics and Traumatology, Prince of Wales Hospital, Shatin, Hong Kong

${ }^{8}$ Department of Orthopaedics and Traumatology, Caritas Medical Centre, Shamshuipo, Hong Kong

* Corresponding author: ksleung@cuhk.edu.hk

New knowledge added by this study

- This was the first study to review the standards and clinical outcomes of 2914 patients from six major hospitals in Hong Kong with fragility hip fracture.

Implications for clinical practice or policy

- Strengths and weaknesses of current fragility hip fracture management were identified. Recommendations are made to improve care.

- This study was the first phase in the process of setting up a Fragility Fracture Registry and reveals the usefulness of a disease registry for improving patient care. 


\section{Introduction}

Fragility hip fracture is one of the most common fragility fractures and is becoming one of the major health care burdens on a society with an ageing population. Statistics of the Hospital Authority (HA) of Hong Kong (HK) reveal that the incidence of fragility fractures in 2014 (14000 cases) was much higher than that for acute myocardial infarction (6383 cases) or acute cerebrovascular accident (11 187 cases). Number of patients admitted for hip fracture surgery increased from 3678 in 2000 to 4579 in 2011, ie $24.5 \%$ in 11 years. ${ }^{1}$ Although the annual age-specific risk of hip fracture slightly decreased, it is estimated that with the projected ageing population, fragility hip fractures in HK will number more than 6300 cases in 2020 and 14500 cases in 2040, a 3-fold increase from 2011. ${ }^{1}$ Approximately $30 \%$ of patients under the age of 80 years were unable to walk independently 1 year after hip fracture and became home-bound; $20 \%$ to $40 \%$ of patients were admitted to an elderly care home; and all patients suffered both physically and psychologically with re-fracture and fear of falls. ${ }^{2}$ Hip fracture patients with poor functional recovery are unable to resume their prefracture function with a consequent deterioration in quality of life. Mortality at 1 year after hip fracture was as high as $27 \%$ in males and $15 \%$ in females. ${ }^{1}$

To monitor the outcomes of management and formulate standards of care in HK for fragility hip fracture, the Coordinating Committee in Orthopaedics \& Traumatology of the HA proposed a Fragility Fracture Registry (www.ffr.hk) in 2013. It is hoped that the registry will ultimately help set the standards of care with respect to local demands, monitor patient care and implement preventive measures, thus improving the cost-effectiveness of fragility fracture care.

In the first phase of setting up the Fragility Fracture Registry, a retrospective study was conducted of fragility hip fractures treated at six acute public hospitals under the management of the HA. This study aimed to review the current fragility hip fracture management in $\mathrm{HK}$, and compare the outcomes with the standards set by our working group with reference to the six evidence-based standards set by the British Orthopaedic Association (BOA) for the care of patients with fragility hip fracture. ${ }^{3}$

\section{Methods}

All patients with fragility hip fracture and admitted in the calendar year 2012 to the six hospitals in HKCaritas Medical Centre, Prince of Wales Hospital, Princess Margaret Hospital, Queen Elizabeth Hospital, Queen Mary Hospital, and Tuen Mun Hospital-which are located in different clusters were included. Residents of HK aged 50 years and

\section{我們治理脆性顝部骨折是否理想? 一個根據脆性} 骨折登記冊數據的敘述報告

\section{梁國穗、袁慧芬、倪偉傑、林楚賢、劉德榮、李建邦、} 邵貴明、鄧寧、黃仕雄、張穎愷

引言：我們在設立香港脆性骨折登記冊的過程中, 對脆性髖部骨折 進行了回顧性研究。把研究所得的結果與我們的矯形工作小組以及 British Orthopaedic Association轄下的脆性骨折登記冊的標準進行比 較。

方法：收集2012年香港6家大型急診醫院的脆性髖部骨折患者的臨床 資料。當中包括人口統計學、術前和術後評估、出院細節、併發症和 1年期隨訪資料。使用根據British Orthopaedic Association而制定的本 地標準來進行分析。

結果：91.0\%的患者在入院4小時內接受骨科護理, 當中 $60.5 \%$ 的患者 於 48 小時內接受手術。3.5\%的患者術前接受了老年矯形外科聯合管理 模式, 是導致 $22 \%$ 患者須延遲手術的原因之一。只有 $22.9 \%$ 患者出院 時獲處方促進骨骼健康的藥物。出院後需要入住護老院的比例增加了 $16.2 \%$ ，達統計學顯著性（ $\mathrm{P}<0.001)$ 。只有 $35.1 \%$ 的患者在骨折 1 年 後有門診隨訪; 當中 $69.9 \%$ 與骨折前比較有病情惡化的情況。患者術 後 1 年死亡率為 $17.3 \%$, 相對地香港年齡匹配人口的死亡率為 $1.6 \%$

結論：本研究記錄了香港脆性䯣部骨折患者急性護理的效用和質素。 定期的老年骨科聯合管理模式可以加強對患者的急性護理。醫護界需 要付出更大努力來讓患者的功能得以恢復、並改善骨骼保健藥物的處 方比率以及患者的隨訪比率, 希望有助減少患者入住護老院的比例。 脆性骨折聯絡服務對改善骨折患者的長期護理和預防繼發性骨折至為 重要。

above with hip fracture sustained by a fall from a standing height were recruited. The number of fragility hip fractures from the six hospitals was approximately $60 \%$ of the total fragility hip fractures treated in Hong Kong during 2012. Those with atypical or pathological fracture were excluded. As $98 \%$ of patients with fragility hip fracture were managed in public hospitals, eligible patients were identified using the HA Clinical Data Analysis and Reporting System with disease coding of acute hip fracture (ICD-9-CM 820.X). ${ }^{4}$ Ethical approvals were obtained from all the six hospitals and the study was done in accordance with the principles outlined in the Declaration of Helsinki.

With reference to the National Hip Fracture Database of the United Kingdom (UK NHFD) and Scottish Hip Fracture Audit, the dataset was designed according to the acute, rehabilitation, and post-discharge practices in HK. Information was derived from the HA Clinical Management System and hospital records for the following: demographics, preoperative and postoperative assessments, surgical and discharge details, rehabilitation details, out-patient follow-up consultations and complications up to 1 year after fracture (Table 1 ). All data were input and managed using the Research Electronic Data Capture (REDCap) tool hosted at the Department of Orthopaedics and Traumatology, 
TABLE I. Data included in this study (a total of 103 data entry items; 70 to 80 items in a typical case)

\begin{tabular}{|c|c|}
\hline Data & Details \\
\hline Demographics & $\begin{array}{l}\text { Age } \\
\text { Gender } \\
\text { Living situation }\end{array}$ \\
\hline Admission information & $\begin{array}{l}\text { Date and time of first presentation } \\
\text { Date and time admitted to } \\
\text { orthopaedic ward }\end{array}$ \\
\hline Operation details & $\begin{array}{l}\text { Type of fracture } \\
\text { Operation } \\
\text { Date and time of operation }\end{array}$ \\
\hline $\begin{array}{l}\text { Preoperative } \\
\text { assessments }\end{array}$ & $\begin{array}{l}\text { ASA grade } \\
\text { Falls assessment } \\
\text { Presence of pressure ulcer } \\
\text { Medical assessment } \\
\text { Bone health medication prescription } \\
\text { Multidisciplinary assessment }\end{array}$ \\
\hline $\begin{array}{l}\text { Postoperative } \\
\text { assessments }\end{array}$ & $\begin{array}{l}\text { Postoperative complications } \\
\text { Medical assessment } \\
\text { Bone health medication prescription } \\
\text { Multidisciplinary assessment }\end{array}$ \\
\hline Discharge details & $\begin{array}{l}\text { Discharge destination from acute } \\
\text { orthopaedic ward } \\
\text { Length of stay on acute ward } \\
\text { Discharge destination from hospital } \\
\text { Unplanned admission }<28 \text { days }\end{array}$ \\
\hline 1 Year after fracture & $\begin{array}{l}\text { Follow-up rate } \\
\text { Mobility } \\
\text { Complication of fracture } \\
\text { Revision surgery } \\
\text { Secondary fracture } \\
\text { Mortality at } 1 \text { year }\end{array}$ \\
\hline
\end{tabular}

Abbreviation: ASA = American Society of Anesthesiologists

Faculty of Medicine, The Chinese University of Hong Kong. ${ }^{5}$

Data were input by research assistants who understood medical terms and abbreviations. Data were validated for one in five cases selected randomly by six liaison teams located in the participating hospitals and composed of orthopaedic surgeons and nurses. Each liaison member was trained by the central research team in data validation and REDCap manipulation.

The data were analysed and compared with the standards set by our working group with reference to the six standards set by the BOA: Care of Patients with Fragility Fractures (known as the Blue Book; Box). ${ }^{3}$

Descriptive statistics were used to describe the current hip fracture conditions in HK and outcomes compared with standards of care from HK orthopaedic working group with reference to BOA. The percentage was calculated based on the number of follow-up patients available at different time-points. Chi squared test was used to compare categorical data. The Statistical Package for the Social Sciences (Windows version 20.0; IBM Corp, Armonk [NY], US) was used to perform statistical analysis. Significance was set at $\mathrm{P}<0.05$.
BOX. Standards for fragility hip fracture care set by working group and the Blue Book ${ }^{3}$

1. *Admission to orthopaedic ward within 4 hours
2. *Surgery within 48 hours and during working hours
3. *Prevention of pressure ulcers
4. *Preoperative assessment by an ortho-geriatrician
5. Optimal surgical and non-surgical management
6. Short stay in acute hospital
7. Speedy discharge home
8. Multidisciplinary sustainable rehabilitation services in
9. the community
10. *Received a falls assessment prior to discharge
11. Prevention of secondary fractures

* Same as the six standards set by the Blue Book

\section{Results}

\section{Demographics}

A total of 2914 fragility hip fractures were captured in the calendar year 2012 and the mean ( \pm standard deviation) patient age was $82.1 \pm 8.6$ years (range, 50-104 years). Of the patients, 1979 (67.9\%) were female; 2017 (73.7\%) came from home and 719 (26.3\%) from an elderly care home; 1119 (40.9\%), 1541 (56.3\%), and 20 (0.7\%) patients had an American Society of Anesthesiologists (ASA) score of grade 2, 3 , and 4 , respectively (Table 2 ).

\section{Acute management}

The mean time from presentation to the accident and emergency department to orthopaedic care was 2.3 hours (median time, 1.7 hours) with $91.0 \%$ patients receiving orthopaedic care within 4 hours. Geriatric or internal medicine review was performed in $764(27.8 \%)$ patients although only 95 (3.5\%) were routinely managed by a geriatrician preoperatively.

Surgery was performed in $2774(96.8 \%)$ patients. The mean time to surgery was 62.7 hours (median time, 42.1 hours) with 1678 (60.5\%) undergoing surgery in exactly 48 hours and 2172 (78.3\%) within 2 calendar working days.

Intracapsular fracture occurred in 1358 (46.6\%) patients of whom 277 (9.5\%) underwent cannulated screw fixation, 829 (28.4\%) uncemented unipolar hemiarthroplasty, and 109 (3.7\%) cemented unipolar hemiarthroplasty. Intertrochanteric fracture occurred in 1446 (49.6\%) patients of whom 571 (19.6\%) underwent compression hip screw fixation and $983(33.7 \%)$ intramedullary fixation (Tables 2 and 3).

During stay in acute hospitals, some of the patients developed acute complications, with nearly one fourth experienced urine retention. A small number of patients developed other complications like pressure sore, delirium, wound infection, and deep vein thrombosis (Table 3). 
TABLE 2. Comparison of demographics, surgery details, and length of stay in acute hospitals between Hong Kong $(\mathrm{HK})$ and the National Hip Fracture Database of the United Kingdom (UK NHFD)

\begin{tabular}{lcc}
\hline & HK (\%) & UK NHFD (\%) \\
\hline Gender & & \\
\hline Female & 67.9 & 74.0 \\
\hline Age (years) & & \\
\hline $60-69$ & 6.3 & 8.3 \\
\hline $70-79$ & 25.2 & 22.2 \\
\hline $80-89$ & 50.0 & 48.2 \\
\hline$\geq 90$ & 18.5 & 21.3 \\
\hline ASA grade† & & \\
\hline 1 & 2.0 & 2.4 \\
\hline 2 & 40.9 & 30.7 \\
\hline 3 & 56.3 & 55.1 \\
\hline 4 & 0.7 & 11.4 \\
\hline 5 & 0.0 & 0.4 \\
\hline Fracture type† & & \\
\hline Intracapsular undisplaced & 10.1 & 10.9 \\
\hline Intracapsular displaced & 36.5 & 46.8 \\
\hline Intertrochanteric & 49.6 & 34.3 \\
\hline Subtrochanteric & 3.8 & 5.4 \\
\hline Other and unknown & 0.0 & 2.6 \\
\hline Surgery & & \\
\hline Yes & 96.8 & 96.5 \\
\hline Mean length of stay in acute & 12.1 & 15.8 \\
\hline nospitals (days) & & \\
\hline
\end{tabular}

Abbreviation: ASA = American Society of Anesthesiologists

* Data are shown in percentages, except otherwise indicated;

$\%$ was calculated based on the number of patients for whom data were available

† Because of rounding, not all percentages total 100

The mean length of stay in acute hospitals was 12.1 days. With regard to the discharge destination from the acute unit, a majority of patients (2284, $78.4 \%$ ) were transferred to a rehabilitation unit, $290(10.0 \%)$ to an old-age home, $236(8.1 \%)$ to their previous home, and 77 (2.6\%) died during the acute admission (Table 3).

\section{Rehabilitation phase}

Allied health professionals provided preoperative multidisciplinary care to 1759 (64.0\%) patients and postoperative care to 2886 (99.4\%). Bone health medication was prescribed to $424(15.3 \%)$ patients preoperatively and 666 (22.9\%) postoperatively. Just over half of all patients $(\mathrm{n}=1573,57.5 \%)$ were discharged to their home and $1163(42.5 \%)$ to an old-age home. Old-age home admission at discharge significantly increased $(\mathrm{P}<0.001)$ [Table 4$]$.
TABLE 3. Summary of hip fracture outcomes in Hong Kong

\begin{tabular}{|c|c|}
\hline Outcome of hip fracture & No. $(\%)$ of patients \\
\hline \multicolumn{2}{|l|}{ Operation type } \\
\hline \multicolumn{2}{|l|}{ Fixation } \\
\hline Compression hip screw & $571(19.6)$ \\
\hline Cannulated screw & $277(9.5)$ \\
\hline Intramedullary & $983(33.7)$ \\
\hline \multicolumn{2}{|l|}{ Hemiarthroplasty } \\
\hline Uncemented unipolar & $829(28.4)$ \\
\hline Cemented unipolar & $109(3.7)$ \\
\hline Uncemented bipolar & $14(0.5)$ \\
\hline Cemented bipolar & $25(0.9)$ \\
\hline Others & $14(0.5)$ \\
\hline
\end{tabular}

Acute complications

Urine retention 675 (23.2)

Pressure sore $153(5.3)$

Delirium $113(3.9)$

Wound infection $81(2.8)$

Deep vein thrombosis $18(0.6)$

Discharge pattern from acute unit

Transferred to rehabilitation unit $\quad 2284$ (78.4)

Discharged to old-age home $290(10.0)$

Discharged home 236 (8.1)

Transferred to non-orthopaedic $18(0.6)$

acute unit

Died during the episode 77 (2.6)

Unplanned re-admission

\begin{tabular}{lc} 
No & $2484(85.2)$ \\
$\begin{array}{l}\text { Complications requiring revision } \\
\text { surgeries }\end{array}$ & $16(0.5)$ \\
$\begin{array}{l}\text { Not related to corresponding hip } \\
\text { fracture episode }\end{array}$ & $396(13.6)$ \\
\hline Another geriatric hip fracture & $6(0.2)$ \\
\hline $\begin{array}{l}\text { Implant breakage or cut-out } \\
\text { Implant loss fixation }\end{array}$ & $38(1.3)$ \\
\hline Fracture mal-union or non-union & $43(1.5)$ \\
Bone infection & $34(1.2)$ \\
Prosthesis complications & $10(0.3)$ \\
\hline
\end{tabular}

\section{Post-discharge management}

There was a declining trend over time for attendance at follow-up; 2179 (74.8\%) attended follow-up at 90 days after fracture, $2508(86.1 \%)$ at 180 days, and only $1023(35.1 \%)$ at 1 year. Postoperative mobility compared with premorbid had deteriorated at 90-day, 180-day, and 1-year follow-up in 1689 (77.5\%), $2062(82.2 \%)$, and $715(69.9 \%)$ patients, respectively. With those 669 patients available for assessments at both 90-day and 1-year time-points, 
TABLE 4. Change in residential status and mobility in Hong Kong

\begin{tabular}{|c|c|c|c|c|}
\hline \multirow{2}{*}{$\begin{array}{l}\text { Premorbid status (or compared with } \\
\text { premorbid status) }\end{array}$} & \multicolumn{3}{|c|}{ Status at discharge or 1 year } & \multirow[t]{2}{*}{$P$ value } \\
\hline & \multicolumn{3}{|c|}{ Residential status: at discharge } & \\
\hline Residential status: premorbid & Home & $\mathrm{OAH}$ & Total & $<0.001$ \\
\hline Home & 1556 & 461 & 2017 & \\
\hline $\mathrm{OAH}$ & 17 & 702 & 719 & \\
\hline \multirow[t]{2}{*}{ Total } & 1573 & 1163 & 2736 & \\
\hline & \multicolumn{3}{|c|}{ Mobility at 1 year (compared with premorbid) } & \\
\hline Mobility at 90 days (compared with premorbid) & Deteriorated & Unchanged or improved & Total & $<0.001$ \\
\hline Deteriorated & 399 & 112 & 511 & \\
\hline Unchanged or improved & 27 & 131 & 158 & \\
\hline \multirow[t]{2}{*}{ Total } & 426 & 243 & 669 & \\
\hline & \multicolumn{3}{|c|}{ Presence of pressure ulcer: at 1 year } & \\
\hline Presence of pressure ulcer: preoperative & Yes & No & Total & $<0.001$ \\
\hline Yes & 12 & 46 & 58 & \\
\hline No & 138 & 2653 & 2791 & \\
\hline Total & 150 & 2699 & 2849 & \\
\hline
\end{tabular}

Abbreviation: $\mathrm{OAH}$ = old-age home

511 patients had deterioration at 90 days and 426 patients deteriorated at 1 year. The deterioration was significant at 1 -year follow-up $(\mathrm{P}<0.001)$ [Table 4]. Pressure sores were evident or developed in $58(2.0 \%)$ patients preoperatively and $150(5.3 \%)$ at 1 year. Presence of pressure sore significantly increased at 1 year $(\mathrm{P}<0.001)$ [Table 4$]$.

Fracture complications occurred in $175(6.0 \%)$ patients within a year (Table 3) with $90(3.1 \%)$ requiring revision surgery. A secondary fracture occurred in 117 (4.0\%) patients and 505 (17.3\%) patients died in 1 year compared with the $1.6 \%$ mortality rate for a HK age-matched population. ${ }^{6,7}$

\section{Discussion}

This report reviewed the management of fragility hip fractures in HK based on the standards of care by our orthopaedic community and compared the outcomes with the standards set by our working group and by BOA in the UK.

The demographics were comparable to previous studies in HK. The mean age of patients with fragility hip fracture in our 2012 data was 82.1 years, unchanged compared with local data from 2000 to $2011 .{ }^{1}$ The female-to-male ratio was around $2: 1$ indicating an increase in male fragility hip fractures compared with 2.5:1 from 2001 to $2010.4,8$ This may be due to increasing life expectancy of the HK male population ${ }^{9}$ and bone mineral density (BMD) at the hip in men that decreases with age. ${ }^{10}$ There were 1257 (46.6\%) femoral neck fractures, 1445 (49.6\%) intertrochanteric fractures, and 110 (3.8\%) subtrochanteric fractures, comparable with a previous local study of 1342 hip fracture patients from 2007 to $2010 .^{8}$ The majority of patients had an ASA score of 2 and 3, comprising $40.9 \%$ and $56.3 \%$, respectively and in line with Lau et al's study. ${ }^{8}$ There was a marked increase in hemiarthroplasties and intramedullary fixations with 977 (33.5\%) and 983 (3.7\%) cases respectively in our study, compared with Lau et al's study that reported $362(27 \%)$ hemiarthroplasties and 218 (16\%) cephalomedullary nail fixations. ${ }^{8}$ This reflects a change in the surgical treatment, possibly due to a lower re-operation rate, ${ }^{11}$ better functional outcomes, ${ }^{12}$ and higher cost-effectiveness $^{13}$ in patients treated with hemiarthroplasty; and minimal rate of fixation failure, less blood loss, and shorter length of hospital stay in patients treated with intramedullary fixation. ${ }^{14}$

A low complication rate (6.0\%) and revision rate $(3.1 \%)$ are testimony to the improved standard of routine acute care, which includes early orthopaedic care and early surgeries.

\section{Consequences of fragility hip fracture}

Poor functional recovery was evident in the large proportion of patients (77.5\%) with deteriorated mobility at 90-day out-patient clinic follow-up, not improved 1 year after fracture (69.9\%). This compares with less than half of treated patients who regained their pre-fracture mobility in another study. ${ }^{15}$ According to an internal survey conducted at Prince of Wales Hospital, only $22 \%$ of patients received out-patient physiotherapy; the major reason $(71 \%)$ was "not referred". Inadequate rehabilitation after discharge may explain poor functional recovery after 
hip fracture. On discharge, HK patients discharged to an old-age home significantly increased from $26.3 \%$ to $42.5 \%$, ie a $16.2 \%$ increase in institutionalisation compared with only $10.5 \%$ in a Spanish study. ${ }^{16}$ Poor functional recovery after hip fracture may contribute to this high institutionalisation rate, as fractures are significantly associated with mildto-severe functional limitations. ${ }^{17}$ Lack of support in the community may mean a lack of sustained rehabilitation after discharge. Family support may also be suboptimal as many elderly are alone at home during the day.

\section{Low follow-up attendance and high mortality}

The attendance rate for out-patient clinic followup was only $35.1 \%$ at 1 year. A high proportion of elderly living alone $(12.7 \% \text { in } 2011)^{18}$ and a high institutionalisation rate $(5.7 \% \text { in } 2014)^{19}$ may explain the low follow-up rate due to lack of support. The mortality at 1 year after fracture was $17.3 \%$, comparable with other local studies: $18.6 \%$ from 2000 to $2006^{1}$ and $18.0 \%$ from 2001 to $2009,{ }^{4}$ which are much higher than that for an age-matched population $(1.6 \%){ }^{6,7}$

\section{Comparison with standards in the United Kingdom}

Data from this review were also compared with those of the UK NHFD $2012^{20}$ collected from 180 hospitals across the UK with patients managed according to the UK Blue Book standards. ${ }^{3}$

Tables 2 and 5 summarise the demographics, surgery details, length of stay in acute hospitals, and comparison of six standards for hip fracture care between HK and UK NHFD, respectively. Major differences in hip fracture management between $\mathrm{HK}$ and UK NHFD are identified.

When comparing the demographics, our review showed a larger male hip fracture population (32\%) than the UK (26\%) while age and ASA grade distribution were similar. Patients treated surgically were similar in both databases; more HK patients had intertrochanteric fracture (49.6\% vs $34.3 \%)$ and more UK patients had displaced intracapsular fracture $(46.8 \%$ vs $36.5 \%)$. The length of stay in acute hospitals in HK was shorter than in UK (12.1 days vs 15.8 days). The mean length of post-acute stay in the UK was only 4.4 days, however, which is shorter than that in HK (around 3-4 weeks). This may be due to the differences in acute and post-discharge care between $\mathrm{HK}$ and the UK. Care by a general practitioner after being discharged from hospital is the usual practice in the UK; in HK, most patients will be cared for by an orthopaedic team in post-acute rehabilitation with follow-up in orthopaedic specialist clinics until discharge.

In $\mathrm{HK}, 98 \%$ of patients underwent a falls assessment on admission, similar to the UK (92\%). In $\mathrm{HK}$, a Morse Fall Scale ${ }^{27}$ will be calculated by orthopaedic nurses on admission; in the UK, a systematic assessment is performed by a geriatrician or a specialist nurse to prevent further falls. ${ }^{8}$

\section{Quick surgery under Key Performance Indicator}

With regard to the six standards for hip fracture care set by the BOA Blue Book (Box and Table 5), $61 \%$ of HK patients had surgery within exactly 48 hours, compared with $35 \%$ in Spain ${ }^{21}$ and less than $10 \%$ in $\mathrm{China}^{22}$; in the UK, $83 \%$ of patients received surgery within 48 hours and during working hours. The percentage of $\mathrm{HK}$ patients who underwent surgery within 2 calendar working days was 30\% before 2007 and improved to $62 \%$ in 2008 after the establishment of Key Performance Indicator (KPI) by the HA and $78.3 \%$ in $2012 .{ }^{23}$ The aim of KPI is to ensure $70 \%$ of hip fracture patients receive surgery within 2 calendar working days. ${ }^{24,25}$ This may explain why a large proportion of patients had quick hip fracture surgery in HK. The delay in surgery for $22 \%$ of patients may have been due to time spent awaiting medical optimisation by physicians or geriatricians.

\section{Importance of geri-orthopaedic co-management}

Very few patients in HK (3.5\%) received preoperative assessment by geriatricians in contrast to $43 \%$ of patients in the UK. In this review, only one of the six studied hospitals had a geriatrician who routinely assessed hip fracture patients pre- and post-

TABLE 5. Comparison of six standards for hip fracture care between Hong Kong (HK) and the National Hip Fracture Database of the United Kingdom (UK NHFD) ${ }^{3}$ in 2012

\begin{tabular}{lcc}
\hline Standard & HK (\%) & UK NHFD (\%) \\
\hline 1. Admission to orthopaedic ward within 4 hours & 91.0 & 52 \\
2. Surgery within 48 hours and during working hours & 60.5 (exactly 48 hours) & 83 \\
3. Patients developing pressure ulcers & 5.3 & 3.7 \\
4. Preoperative assessment by an ortho-geriatrician & 3.5 & 43 \\
5. Discharged with bone protection medication & 22.9 & 69 \\
6. Received a falls assessment prior to discharge & 98 & 92 \\
\hline
\end{tabular}


operatively, indicating a lack of geri-orthopaedic co-management in HK. Studies have shown better outcomes after hip fracture when patients receive geri-orthopaedic treatment, with a lower 1-year mortality rate, ${ }^{26,27}$ reduced acute hospital stay, and less need for further rehabilitation. ${ }^{27}$ A local study reviewed the effectiveness of geri-orthopaedic comanagement and found that in the geri-orthopaedic group, time to surgery was shorter, 1-year mortality rate was lower, and more remained independent in daily living activities. ${ }^{28}$ Therefore, geri-orthopaedic care should be implemented in all hospitals in HK to achieve better patient care. This will further improve the KPI for fragility hip fractures in all hospitals in HK.

\section{Low prescription rate of bone protection medication}

Only $23 \%$ of $\mathrm{HK}$ patients were discharged with bone protection medication compared with almost $70 \%$ in the UK (Table 5) and nearly $40 \%$ in Korea (excluding calcium and vitamin D). ${ }^{29}$ A local study showed that $33 \%$ were prescribed medications for osteoporosis in the 6 months after discharge. ${ }^{30}$ Osteoporosis diagnosis and treatment were driven by BMD measurement, not fracture history. ${ }^{30}$ This may explain the low prescription rate of bone protection medication when the fracture patient did not undergo BMD measurement for a variety of reasons such as unavailability of dual-energy X-ray absorptiometry (DXA), long queuing time, or lack of referral from orthopaedic doctors. Although the need for DXA measurement prior to prescription of bone health medication to patients with fragility fracture remains controversial, it is clear that DXA measurement is not the only single indication for such medication. ${ }^{31}$

\section{Importance of Fracture Liaison Services}

In view of the low follow-up rate, poor functional recovery, increased institutionalisation, and high mortality after fragility hip fracture, better postdischarge rehabilitation and secondary fracture prevention should be implemented to restore patients' physical and psychological status.

Fracture Liaison Services (FLS) is a coordinatorbased service for sustained rehabilitation in the community and secondary fracture prevention in patients with fragility fractures. It has been implemented in many countries-eg the UK, ${ }^{32}$ Australia, ${ }^{33}$ Canada $^{34}$-and studies reveal that FLS is cost-effective. Implementation of FLS in HK may improve current post-discharge care. Such services include osteoporosis identification and treatment (eg DXA scan and prescription of bone protection medication), education about secondary fracture prevention (exercise, dietary guidelines, and an education programme), and sustainable multidisciplinary services (follow-up by FLS coordinator regularly). With FLS, fragility hip fracture patients with osteoporosis can be identified and treated promptly with good compliance with medications. Patients will be instructed to exercise to improve functional status with a potential consequent decrease in old-age home admission. They will also be taught about falls prevention and sustained rehabilitation, and hence lower the chance of secondary fracture.

\section{Limitations of this study}

This study included approximately $60 \%$ of all HK fragility hip fractures. It would be better to include all HK hospitals in future studies to reflect the full situation across the territory. This study retrospectively reviewed medical records from 2012 with data retrieved from electronic and handwritten records so a small percentage of data may have been missing due to illegible records. A standardised electronic format from the Clinical Management System will improve data capture and analysis. A disease registry is important to enable better documentation.

\section{Conclusions}

This study reviewed the current fragility hip fracture care in HK. Although acute surgical treatment complies with international standards, standardised geri-orthopaedic co-management will further improve the acute care. Recognising fragility hip fracture as a chronic disease model, the increased rate in old-age home admission, poor functional recovery, low prescription rate of bone health medications, and low attendance rate for followup were identified as problems in subsequent management. These may explain the higher 1-year mortality rate, high secondary fracture rate, and deterioration in the quality of life after fracture among these elderly. With an ageing population and increasing longevity, the hip fracture rate is expected to increase continuously. A comprehensive multidisciplinary chronic disease management model that includes geri-orthopaedic co-management and FLS programmes should be implemented to improve patient outcomes, prevent secondary fractures, and reduce the economic burden on $\mathrm{HK}$. The setting up and maintenance of a registry of all fragility fractures is imminent and will help health care professionals monitor and continuously improve the standards of patient care as well as prevent fractures.

\section{Acknowledgements}

This study was partially supported by grant support of Asian Association for Dynamic Osteosynthesis (Ref: AADO-RF2012-001-2Y) and Professional Services Development Assistance Scheme, Commerce and 
Economic Development Bureau, Government of the Hong Kong Special Administrative Region. The authors would like to thank the liaison teams that comprised doctors and nurses of the Department of Orthopaedics and Traumatology from the six participating hospitals for their help in data validation.

\section{Declaration}

All authors have disclosed no conflicts of interest.

\section{References}

1. Man LP, Ho AW, Wong SH. Excess mortality for operated geriatric hip fracture in Hong Kong. Hong Kong Med J 2016;22:6-10.

2. Fierens J, Broos PL. Quality of life after hip fracture surgery in the elderly. Acta Chir Belg 2006;106:393-6.

3. The care of patients with fragility fracture. British Orthopaedic Association; 2007.

4. Chau PH, Wong M, Lee A, Ling M, Woo J. Trends in hip fracture incidence and mortality in Chinese population from Hong Kong 2001-09. Age Ageing 2013;42:229-33.

5. Harris PA, Taylor R, Thielke R, Payne J, Gonzalez N, Conde JG. Research electronic data capture (REDCap) - a metadata-driven methodology and workflow process for providing translational research informatics support. J Biomed Inform 2009;42:377-81.

6. Population estimates. Census and Statistics Department, Hong Kong SAR Government; 2016.

7. Tables on health status and health services 2012. Department of Health, Hong Kong SAR Government; 2013.

8. Lau TW, Fang C, Leung F. The effectiveness of a geriatric hip fracture clinical pathway in reducing hospital and rehabilitation length of stay and improving short-term mortality rates. Geriatr Orthop Surg Rehabil 2013;4:3-9.

9. Women and men in Hong Kong key statistics. Census and Statistics Department, Hong Kong SAR Government; 2016.

10. Lau EM, Leung PC, Kwok T, et al. The determinants of bone mineral density in Chinese men-results from Mr. Os (Hong Kong), the first cohort study on osteoporosis in Asian men. Osteoporos Int 2006;17:297-303.

11. Shields E, Kates SL. Revision rates and cumulative financial burden in patients treated with hemiarthroplasty compared to cannulated screws after femoral neck fractures. Arch Orthop Trauma Surg 2014;134:1667-71.

12. Gjertsen JE, Vinje T, Engesaeter LB, et al. Internal screw fixation compared with bipolar hemiarthroplasty for treatment of displaced femoral neck fractures in elderly patients. J Bone Joint Surg Am 2010;92:619-28.

13. Waaler Bjornelv GM, Frihagen F, Madsen JE, Nordsletten L, Aas E. Hemiarthroplasty compared to internal fixation with percutaneous cannulated screws as treatment of displaced femoral neck fractures in the elderly: cost-utility analysis performed alongside a randomized, controlled trial. Osteoporos Int 2012;23:1711-9.

14. Ma KL, Wang X, Luan FJ, et al. Proximal femoral nails antirotation, Gamma nails, and dynamic hip screws for fixation of intertrochanteric fractures of femur: a metaanalysis. Orthop Traumatol Surg Res 2014;100:859-66.

15. Vochteloo AJ, Moerman S, Tuinebreijer WE, et al. More than half of hip fracture patients do not regain mobility in the first postoperative year. Geriatr Gerontol Int
2013;13:334-41.

16. Uriz-Otano F, Pla-Vidal J, Tiberio-López G, Malafarina V. Factors associated to institutionalization and mortality over three years, in elderly people with a hip fracture-An observational study. Maturitas 2016;89:9-15.

17. Woo J, Ho SC, Yu LM, Lau J, Yuen YK. Impact of chronic diseases on functional limitations in elderly Chinese aged 70 years and over: a cross-sectional and longitudinal survey. J Gerontol A Bio Sci Med Sci 1998;53:M102-6.

18. Thematic report: older persons. Census and Statistics Department, Hong Kong SAR Government; 2011.

19. Challenges of population ageing. Research Brief, Issue 1, 2015-2016. Hong Kong: Research Office, Legislative Council Secretariat; 2015.

20. National report 2012. The UK National Hip Fracture Database; 2012.

21. Vidán MT, Sánchez E, Gracia Y, Marañón E, Vaquero J, Serra JA. Causes and effects of surgical delay in patients with hip fracture: a cohort study. Ann Intern Med 2011;155:226-33.

22. Tian M, Gong X, Rath S, et al. Management of hip fractures in older people in Beijing: a retrospective audit and comparison with evidence-based guidelines and practice in the UK. Osteoporos Int 2016;27:677-81.

23. Lau PY. To improve the quality of life in elderly people. Hong Kong Med J 2016;22:4-5.

24. New framework for key performance indicators (AOMP530). Hong Kong: Hospital Authority; 2008.

25. Guidebook on key performance indicators. 2nd ed. Hong Kong: Hospital Authority; 2015.

26. Folbert EC, Hegeman JH, Vermeer M, et al. Improved 1 -year mortality in elderly patients with a hip fracture following integrated orthogeriatric treatment. Osteoporos Int 2017;28:269-77.

27. Henderson CY, Shanahan E, Butler A, et al. Dedicated orthogeriatric service reduces hip fracture mortality. Ir J Med Sci 2017;186:179-84.

28. Leung AH, Lam TP, Cheung WH, et al. An orthogeriatric collaborative intervention program for fragility fractures: a retrospective cohort study. J Trauma 2011;71:1390-4.

29. Kim SC, Kim MS, Sanfélix-Gimeno G, et al. Use of osteoporosis medications after hospitalization for hip fracture: a cross-national study. Am J Med 2015;128:51926.e1.

30. Kung AW, Fan T, Xu L, et al. Factors influencing diagnosis and treatment of osteoporosis after a fragility fracture among postmenopausal women in Asian countries: a retrospective study. BMC Womens Health 2013;13:7.

31. Ito K, Leslie WD. Cost-effectiveness of fracture prevention in rural women with limited access to dual-energy X-ray absorptiometry. Osteoporos Int 2015;26:2111-9.

32. McLellan AR, Gallacher SJ, Fraser M, McQuillian C. The fracture liaison service: success of a program for the evaluation and management of patients with osteoporotic fracture. Osteoporos Int 2003;14:1028-34.

33. Cooper MS, Palmer AJ, Seibel MJ. Cost-effectiveness of the Concord Minimal Trauma Fracture Liaison service, a prospective, controlled fracture prevention study. Osteoporos Int 2012;23:97-107.

34. Bogoch ER, Elliot-Gibson V, Beaton DE, Jamal SA, Josse RG, Murray TM. Effective initiation of osteoporosis diagnosis and treatment for patients with a fragility fracture in an orthopaedic environment. J Bone Joint Surg Am 2006;88:25-34. 